\title{
Data Driven Analysis of Startup Accelerators
}

\author{
Krishna Regmi ${ }^{1, *}$, Syed Adeel Ahmed ${ }^{2}$, Mark Quinn $^{3}$ \\ College of Engineering, University of New Orleans, United States
}

Copyright (C) 2015 The University of New Orleans, All rights reserved.

\begin{abstract}
The startup accelerators help nascent startups grow by providing funding and resources. This paper summarizes a data driven analysis of startup accelerators success and presents their growth trends. The goal of this paper was to assess the effectiveness of accelerators. The methodology was to use data to compare US startups that went through the accelerator program with the startups many of which according to Kauffman Foundation failed within 5-6 years, and the businesses that went through accelerator program outside of the US. Data for accelerators was collected from seed-db.com and was filtered for those that were established from 2005-2014. The data shows that the number of accelerators in the US is in the rise, although the growth has slowed down significantly after a very high rise in 2012. Startups that graduated from accelerator programs have approximately $23 \%$ higher survival rate than other new businesses.
\end{abstract}

Keywords Startups, Accelerators, Data Analysis, Venture Capitalist, Startup Success

\section{Introduction}

\subsection{Motivation}

Startup accelerators have become the topic of a lot of discussion in the media lately. Because of their novelty, they have not been studied as thoroughly as other forms of business mentorship programs such as small business mentorships. Many experts have made remarks on whether the accelerators are good or not. For example [10], [11] says that $90 \%$ of the accelerators fail but do not provide any form of concrete data to back it up. Few like [12] have taken specific accelerators and shown their successes. However, the availability of analysis of aggregate of accelerators was missing. This paper fills that gap by exploring startup accelerators (or accelerators), by understanding their successes and their growth trends.

\subsection{Introduction to Accelerators}

Accelerators are organizations that help nascent ventures get a jumpstart by providing them with funds and resources in exchange for partial equity of the company. Unlike other business assistance programs, they have a competitive application process. Startups are required to answer questions about its business model, and founders. Some accelerators such as Y-Combinator are so competitive that less than 3\% of the applicants are selected [7].

Most startups face problems such as lack of experienced management, processes and resources. The problem is compounded by the fact that technology startups usually require a lot more resources in the development phase[4]. As such startups need a partner that understands the perils of a startup and is willing to take various forms of risk with the startup. Startup founders usually are unable to produce enough collateral for a traditional business loan[1] because of expensive nature of technology development. Hence, most of the startups are funded by Venture Capitalists at the growth phase. However, recent trend shows that VCs invest more on later stage startup and the dollar amount of investment usually exceeds 1-2 Million Dollars[5]. As such the need for organization willing to help startups in their early stage with small sums of money and other resources arises. Accelerators fill that need. Accelerators support startups until they are ready to acquire VC funding.

\subsection{What do Startups Get Out of Accelerators?}

Paul Miller and Kirsten Bound, two graduate students in the UK conducted several interviews to find out what founders felt like the best advantage of joining an accelerator program. Some of the answers of the founders are explained below:

\subsubsection{Funding}

Miller[1] reports that most founders agree that funding is one of the main advantage of joining an accelerator. Having funds helps founders focus on the startup rather than making lives meet. This is essential since speed to commercialization is of essence for any startup.

\subsubsection{Networking with VCs}

Accelerators offer unparalleled access to the investors. Most offer face to face sessions with venture capitalists in addition with the graduation day when each startup is 
allowed to pitch their idea to a crowd of investors.

\subsubsection{Product Advice/ Business Advice}

Accelerators offer exposure to other founders. This allows new founders to get feedback on their product and business. This advice is much more valuable to the new founders because it comes from seasoned founders that have been in their shoes.

\subsubsection{Validation}

Being accepted in an accelerator is a validation that the startup has potential. This will not only boost the founder's confidence, but also the credibility of his/her business.

\subsubsection{Peer Support}

Most accelerators have co-working spaces where founders can interact amongst themselves regarding their experiences. This creates an environment where founders can learn from each other.

\section{Data Collection and Criteria}

The data used for this paper was extracted from seed-db.com with the permission of the website operator. Over $226 \mathrm{web}$ pages were traversed to gather data on over 165 accelerators and over 4800 startups established since 2005 worldwide. All the startups that are included in the dataset were the ones that had gone through an accelerator program. Python software and Excel was used to process the data. All the accelerators without an established date was removed from the dataset. Data from year 2005-2014 was used to gather information on accelerators while data from 2005-2013 was used to gather data on startups because of the incomplete nature of startup data for this year.

\section{Accelerators and Startup Growth Trends}

\subsection{Growth Trends}

The advent of modern day startup accelerator happened in 2005 with the establishment of Y-Combinator by Paul Graham[7]. Ever since a lot more accelerators have been established. The following charts presents accelerators established to date.

As we can see from figure 1, the number of new startups established worldwide has been steadily positive. The growth rate of new accelerators has started to decrease since 2012.

Growth in the number of accelerators can be reflected in the number of startups using the accelerators. The chart below shows the number of startups graduated each year since 2005.

As we can see the number of startups has continuously grown since 2005. Despite the increase in number of accelerators in 2012, the number of startups didn't increase in 2013.

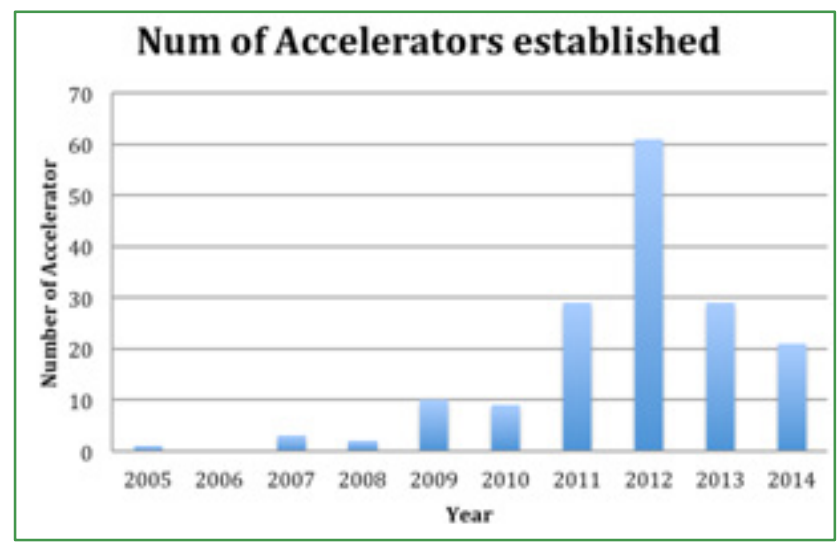

Figure 1. Number of accelerators established

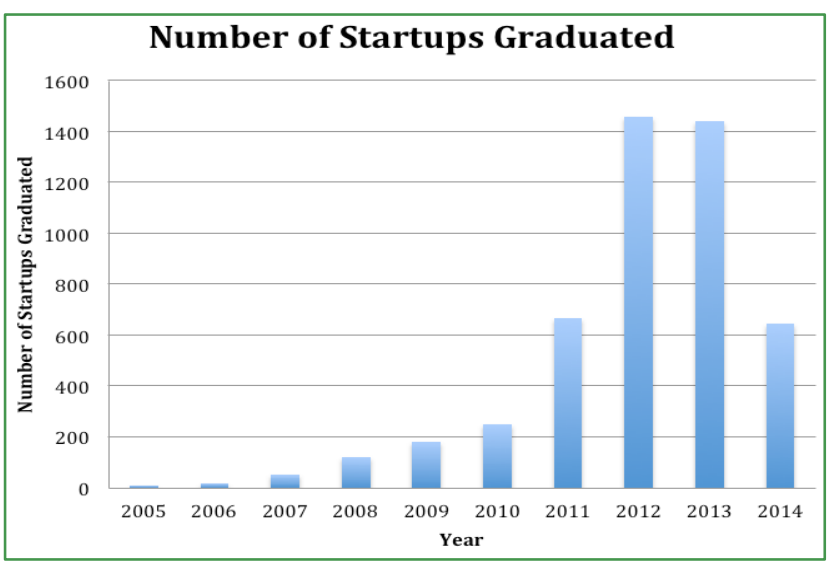

Figure 2. Number of startups graduated

Next, we compare the growth of accelerators in the US vs the rest of the world.

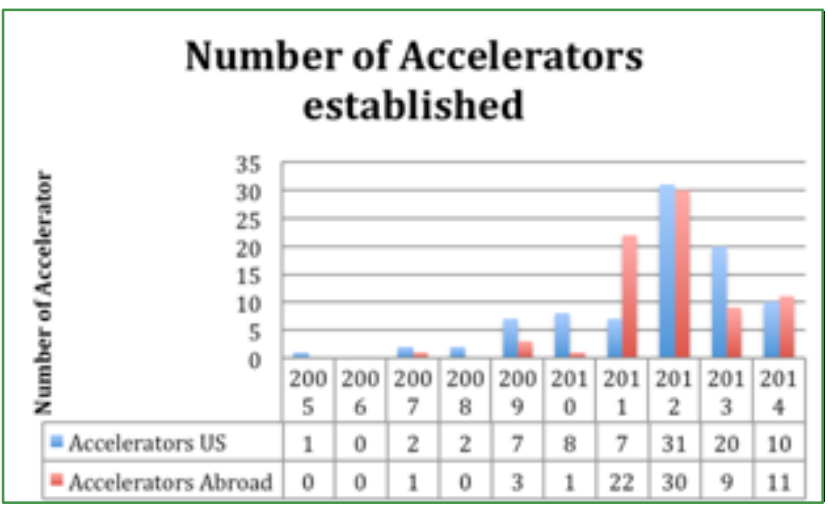

Figure 3. Comparision of accelerators in US vs the world

The trends in the US and abroad are similar. There was a big surge in the number of accelerators established in 2012. For outside of the US, there was a big spike in 2011 as well. 2013 and 2014 saw a pretty steady increase in accelerators outside of the US.

Next, we look at the trends in startup graduation in the US vs abroad. 


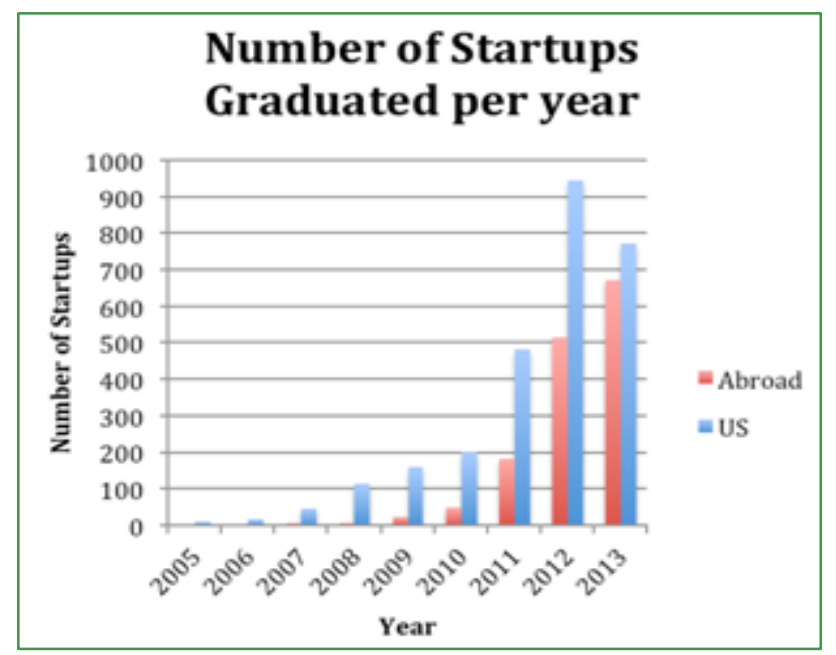

Figure 4. number of startups graduated per year

The number of startups outside of US continues to see continued growth. US saw the largest number of startups established in 2012. There was a slight decrease in the number in 2013.

\subsection{Discussions}

There is no doubt that there is a continuous growth of both accelerators and consequentially the growth in startups. The growth in accelerators seems to be slowed down both in the US and abroad. One of the potential reasons for the slowed growth could be saturation in the market of accelerators, i.e. there isn't enough market for any more accelerators. At the moment, there are 88 accelerators in the US.

Another potential reason can be because of expanding operations of accelerators. Recently, many accelerators are expanding into other cities and countries. Hence, instead of the new accelerators being started, existing ones are expanding to newer locations. This is particularly true for US accelerators. Many of them have programs in two cities in the US. Here is a small list of global accelerators:

- DreamItVentures (US, Isreal)

- HAXLR8RLink(US, China)

- Oxygen Accelerator(US, UK)

\section{Survival Rate of Startups graduated from accelerators}

One criterion to understand how well the accelerators are doing is to measure weather the startups are surviving longer as a result of participation in the accelerator. For a startup to be considered survived, it has to be operational or be acquired by a different company (exited). In this model of measureing accelerator success, if the startups survive longer as compared to other business, the accelerator model is considered valuable. Our baseline comes from two sources. The Bureau of Labor Statistics data shows that 49\% small businesses survive 5 years or more [8] and Census data reports that $69 \%$ businesses survive 2 years or more[9].
The table below shows the current success of startups established at 2012 or before.

Table 1. Success beyond 2 years

\begin{tabular}{|c|c|c|c|c|}
\hline \multicolumn{5}{|c|}{ Success beyond 2 years. [estd at or before 2012] } \\
\hline & US & Abroad & Total & $\begin{array}{c}\text { US Small } \\
\text { Business }\end{array}$ \\
\hline Operating & 1545 & 662 & 2207 & \\
\hline Exited & 206 & 24 & 230 & \\
\hline Dead & 234 & 64 & 298 & \\
\hline Success\% & 88 & 91 & 89 & 70 \\
\hline
\end{tabular}

As we can see in the table above, the startups that graduated from an accelerator program in the US have almost $26 \%$ better odds than a normal US small business.

The table below shows the current success of startups established at or before 2009 .

Table 2. Success beyond 5 years

\begin{tabular}{|c|c|c|c|c|}
\hline \multicolumn{5}{|c|}{ Success beyond 5 years [estd at or before 2009] } \\
\hline & US & Abroad & Total & $\begin{array}{c}\text { US Small } \\
\text { Business }\end{array}$ \\
\hline Operating & 76 & 7 & 83 & \\
\hline Exited & 42 & 3 & 45 & \\
\hline Dead & 65 & 3 & 68 & \\
\hline Success\% & 64 & 77 & 65 & 49 \\
\hline
\end{tabular}

As we can see in table 2, startups that graduated from an accelerator program have almost $23.5 \%$ better odds of surviving than a normal US small business.

From Table 1 and 2, we can conclude that the accelerators are doing really well for the startups. Additionally it is interesting to note that the startups abroad are more successful than the startups in the US. One of the possible reasons for this is because startups abroad have a smaller accelerator to startup ratio. The table below shows the startup to accelerator ration in the US and abroad. The table uses all the accelerators established vs. all the startups established before 2012 .

Table 3. Startups to accelerator ratio in US vs Abroad.

\begin{tabular}{|c|c|c|c|}
\hline & accelerator & startups & ratio \\
\hline US & 88 & 1985 & 22.5 \\
\hline Abroad & 77 & 750 & 9.75 \\
\hline
\end{tabular}

As we can see (table 3), the ratio of startup to accelerator is much smaller abroad than in the US. This potentially provides more attention to the startups abroad than the US.

\section{Conclusions}

In conclusion, the startup accelerators are doing great for the startups. They are a great resource for both funding and business expertise that a startup can use. Figure 1,2,3 and 4 shows that the growth in number of accelerator established is slowing down after the big peak in 2012. Possible causes for 
this decline can be either market saturation or expansion of existing accelerator program into different locations. Tables 1 and 2 show that accelerators increase the odds of a startup survival by around $25 \%$. The startups abroad have a better success rate. One of the possible reasons is smaller startup to accelerator ratio abroad as compared to the US. In summary, accelerators are helping create value to the startups and helping them succeed and the accelerator model of business mentorships seems to be performing better than other forms of business mentorships.

\section{Recommendations for Future Study}

Below are the recommendations for future study.

1. Accelerator's income is not considered. It could be a key marker of success for accelerators.

2. Startups' income or exit value is not considered. Such a consideration will increase the insights on how they are doing.

3. Negative effects of accelerators should be studied.

\section{Acknowledgements}

We are very grateful to seed-db.com's founders. Without the data collected by them, this paper wouldn't have been possible.

\section{REFERENCES}

[1] P. Miller, K. Bound. The Startup Factories, Nesta Publication, 50-53.
[2] D. Hoffman, N. Radojevich-Kelley. Analysis of Accelerator Companies: An Exploratory Case Study of Their Programs, Processes, and Early Results, Small Business Institute Journal 2012, Vol. 8, No. 2, 54-70

[3] C. Chang. Portfolio Company Selection Criteria: Accelerators vs Venture Capitalists, 2013, CMC Senior Thesis. Paper 566. http://scholarship.claremoung.edu/cmc th eses/566

[4] Kathleen Allen, Entrepreneurship for Scientists and Engineers, Pearson Education Inc, USA, 2010.

[5] K. Jin-Hyuk, W. Liad. Portfolio and Information Disclosure: An Analysis of Startup Accelerators, Midwest Finance Association Annual Meeting Paper, 2013.

[6] Straight, Daniel, Interview, 2014

[7] Lee, Jennifer. Running a Hatchery for Replicant Hackers, New York Times, published February 21, 2006

[8] An Overview of the Kauffman Firm Survey: Results from 2011 Business Activities, Prepared By: Alicia Robb and Joseph Farhat, June 2013.

[9] U.S. Dept. of Commerce, Census Bureau, Business Dynamics Statistics; U.S. Dept. of Labor, Bureau of Labor Statistics, BED

[10] Relan, Peter, 90\% of Incubators and Accelerators will Fail and That's Just Fine for America and the World, TechCrunch, October 2012.

[11] Carr, Austin. Most Accelerators Will Fail, So Choose Wisely, FastCompany.com.

[12] Jorgenson, N.M Whats the success rate of startups that have been funded by Y Combinator? Retrived February 18, 2013 from Quora: https://www.quora.com/Whats-the-success-rate -of-startups-that-have-been-funded-by-Y-Combinator 